Family Profile No. 19, 2017

\title{
Mothers Aged 40-44 with Four or More Births
}

Authors: Maurice Anyawie

Although American women have an average of two births by the end of their childbearing years (CDC/NCHS, 2015; Livingston, 2015), it is not uncommon for women to have more than two births. Yet little is known about the characteristics of women with larger families. In this profile, we use the most recent cycle of the National Survey of Family Growth, representing the year 2013, to examine the socio-demographic characteristics of mothers aged 40-44 with four or more births. Figure 1. Crossover in the Median

- About one in seven (15\%) mothers, aged $40-44$ had four or more births (Figure 1). One-quarter (26\%) of mothers had three births, $39 \%$ had two births, and $20 \%$ had just one birth.

- Mothers with more births typically started having their births at younger ages (not shown). Mothers who had only one waited the longest, with a median age at first birth of 28 . Conversely, mothers with four or more births began childbearing earlier, with a median age of 19.

Figure 1. Percentage Distribution of Number of Births among Mothers Aged 40-44

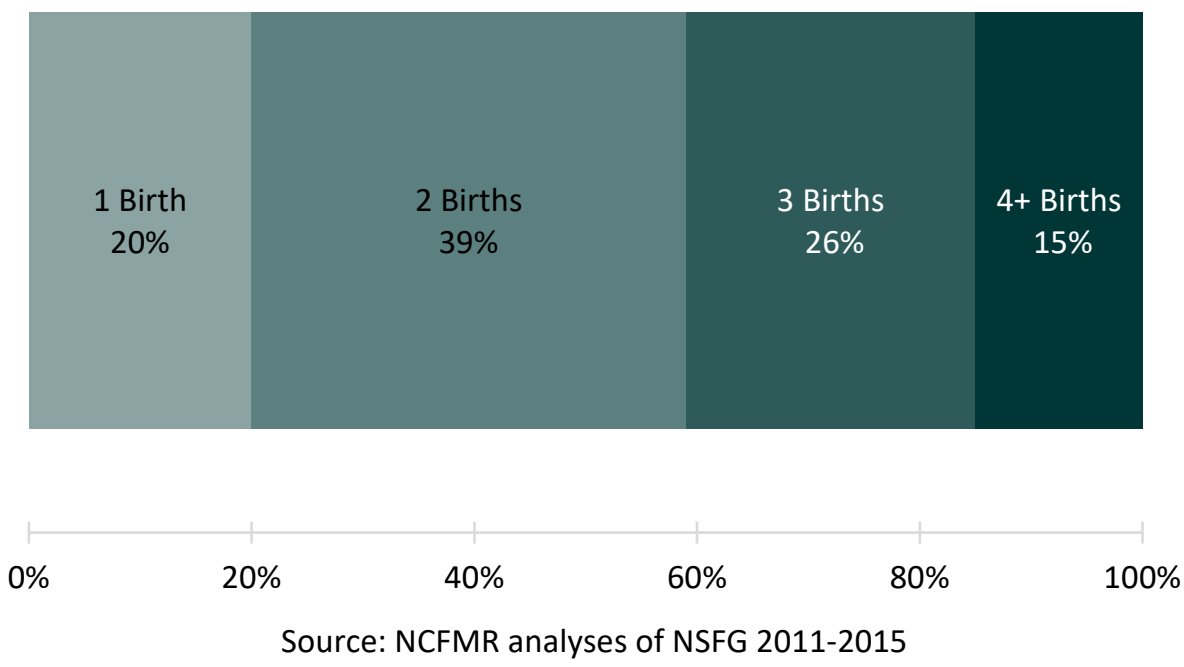

\section{Union Status at First Birth}

The proportion of mothers with four or more births was highest among those single at first birth and lowest among those married at first birth. Half of all women who became mothers in 2015 had their first child after age 26.7, which represents a historic high point in the median age at first birth.

- Nearly three in ten (29\%) mothers who were single at the time of their first birth had four or more births by their early-to-mid forties.

- One-fifth of mothers who were cohabiting at their first birth had four or more births.

- Only one in ten mothers who was married at their first birth gave birth to four or more children.
Figure 2. Percentage of Mothers Aged 40-44 with Four or More Births by Union Status at First Birth

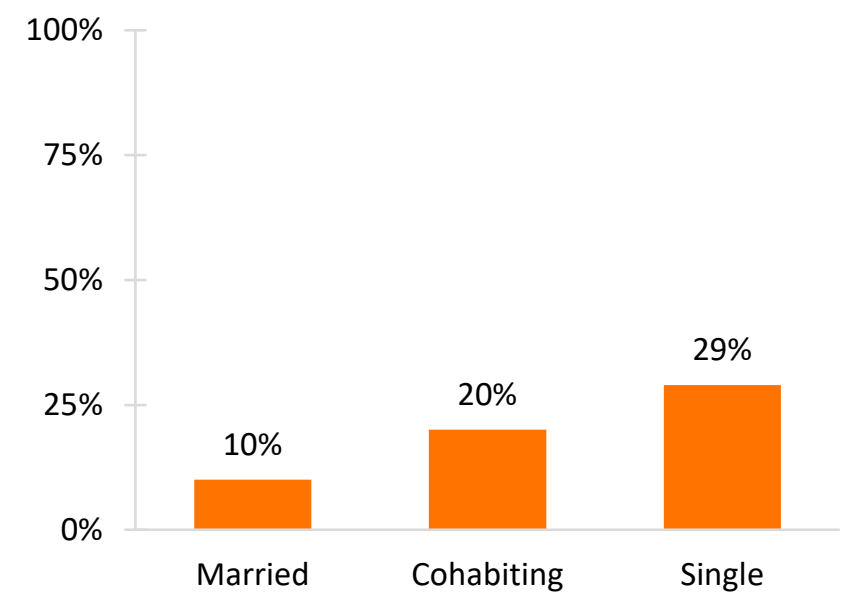

Source: NCFMR analyses of NSFG 2011-2015 
Race and Ethnicity

Larger shares of racial-ethnic minority mothers had four or more births by their early forties compared to their White counterparts.

- Nearly three in ten (29\%) Black mothers and approximately two in ten (22\%) Hispanic mothers had at least four births.

- About one in ten White mothers reported having four or more births by age $40-44$.

\section{Educational Attainment}

Generally, there is an inverse relationship between maternal education and having four or more births.

- Among those in their early-to-mid forties, the proportion of mothers who had at least four births was highest (36\%) among mothers who did not complete high school.

- Among those with a high school degree but no college degree, about $13-14 \%$ had four or more births.

- Mothers who earned a Bachelor's degree or more had the lowest share with four or more births.
Figure 3. Percentage of Mothers Aged 40-44 with Four or More Births by Race/Ethnicity

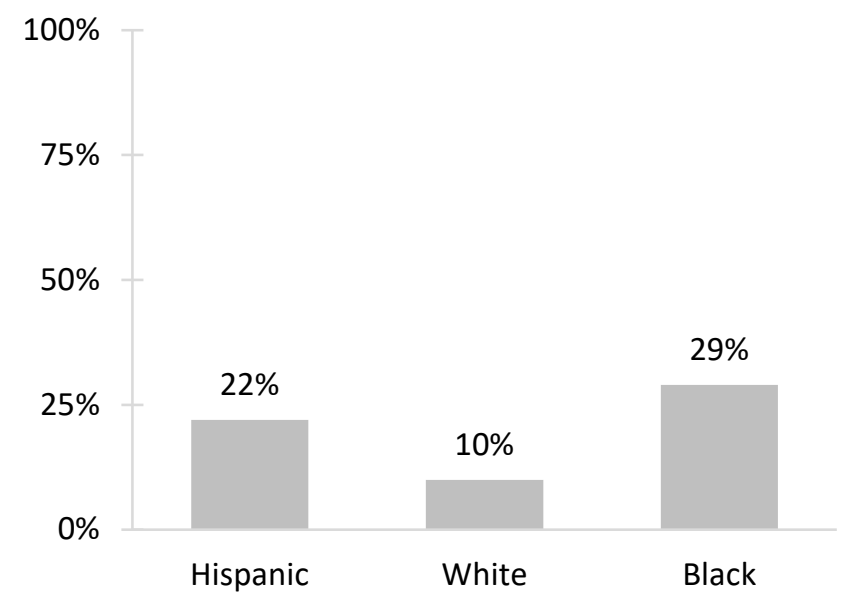

Source: NCFMR analyses of NSFG 2011-2015

Figure 4. Percentage of Mothers Aged 40-44 with Four or More Births by Educational Attainment

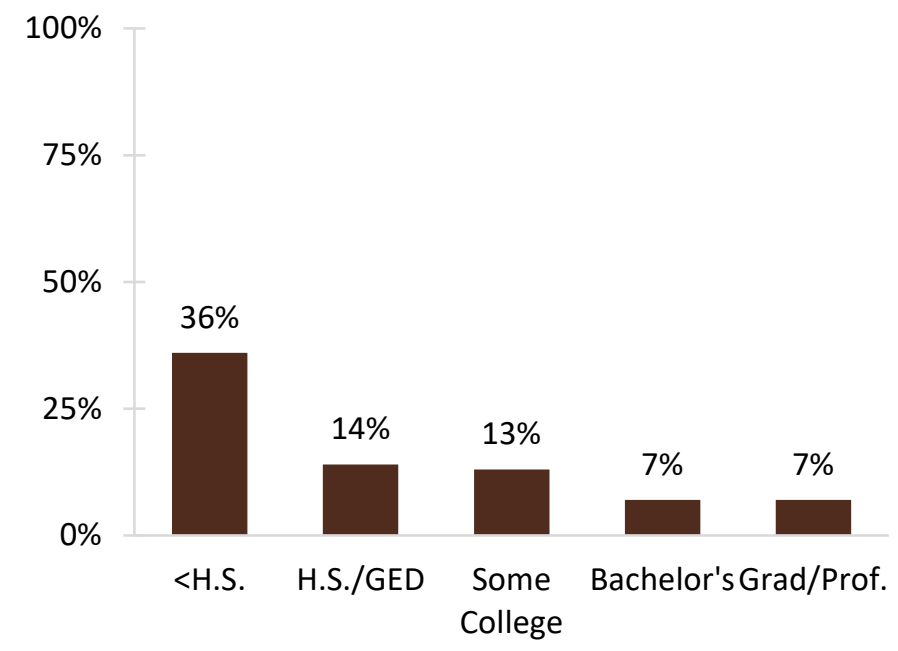

Source: NCFMR analyses of NSFG 2011-2015

\section{References}

CDC/National Center of Health Statistics. \{2015) Births (mothers). Retrieved from

http://www.cdc/nchs/nsfg/key_statistics/b.htm\#birthsmothers Livingston, G. \{2015). Childlessness falls, family size grows among highly educated women. Retrieved from http://assets. pewresearch.org/wp-content/ploads/sites/3/2015/05/2015-05-07_childrenever-born_FINAL.pdf

\section{Suggested Citation:}

Anyawi, M. (2017). Mothers aged 40-44 with four or more births. Family Profiles, FP-17-19. Bowling Green, OH: National Center for Family \& Marriage Research. https://doi.org/10.25035/ncfmr/fp-17-19 